\title{
Yield stress, volume change, and shear strength behaviour of unsaturated soils: validation of the SFG model
}

\author{
Annan Zhou and Daichao Sheng
}

\begin{abstract}
The model recently presented by Sheng, Fredlund, and Gens, known as the SFG model, provides a consistent explanation of yield stress, shear strength, and volume change behaviour of unsaturated soils as functions of suction. All these functions are based on one single equation that defines the volume change with suction and stress changes. This paper provides a systematic validation of the equation and the derived shear strength criterion against experimental data. The experimental data used include those for samples prepared from slurry soils and compacted soils. It is shown that $(i)$ the method currently used to determine yield stresses of unsaturated soils is incorrect, (ii) volume change behaviour of unsaturated soils can be well predicted by the SFG model, and (iii) shear strength behaviour of unsaturated soils can be represented very well by the criterion in the SFG model.
\end{abstract}

Key words: unsaturated soils, volume change, yield stress, shear strength, elastoplastic modelling, Sheng, Fredlund, and Gens (SFG) model.

Résumé : Le modèle présenté récemment par Sheng, Fredlund et Gens, connu sous le nom de modèle SFG, offre une explication consistante de la limite d'écoulement, de la résistance au cisaillement et du comportement lors de variation de volume des sols non saturés en fonction de la succion. Toutes les équations sont basées sur une équation simple qui défini la variation de volume selon la succion et la variation des contraintes. Cet article présente une validation systématique de cette équation et du critère de résistance au cisaillement dérivé de cette équation à partir de données expérimentales. Les données expérimentales utilisées comprennent celles provenant d'échantillons de sols boueux et de sols compactés. Il est démontré que (i) la méthode présentement utilisée pour déterminer la limite d'écoulement de sols non saturés est incorrecte, (ii) le comportement lors de variation de volume de sols non saturés peut être bien prédit par le modèle SFG et (iii) le comportement en résistance au cisaillement de sols non saturés peut être bien représenté par le critère du modèle SFG.

Mots-clés : sols non saturés, variation de volume, limite d'écoulement, résistance au cisaillement, modélisation élastoplastique, modèle de Sheng, Fredlund et Gens (SFG).

[Traduit par la Rédaction]

\section{Introduction}

The emergence of unsaturated soil mechanics in the last 20 years or so is mainly due to two facts: $(i)$ most soil mechanics principles developed in the first 40 years of soil mechanics history apply to saturated soils only and (ii) the distinct volume, strength, and flow characteristics are observed when certain soils become unsaturated with water. Therefore, the key issue in constitutive modelling of unsaturated soils is how the volume and shear strength behaviour can be considered in a consistent framework both for saturated and unsaturated states. However, most existing constitutive models for unsaturated soils employ separate empirical functions to describe volume change, yield stress, and shear

Received 31 May 2008. Accepted 17 April 2009. Published on the NRC Research Press Web site at cgj.nrc.ca on 25 August 2009.

A. Zhou and D. Sheng. ${ }^{1}$ Centre for Geotechnical and Materials Modelling, School of Engineering, The University of Newcastle, Callaghan, NSW 2308, Australia.

${ }^{1}$ Corresponding author (e-mail:

daichao.sheng@newcastle.edu.au). strength behaviour, and these functions may not be consistent with each other or with well-established relations for saturated soils (Sheng et al. 2008a, 2008b). For example, the method currently used to determine yield stresses for unsaturated soils is not consistent with the classical definition of yield stress and can be misleading.

In the literature of unsaturated soil mechanics, the yield stress of an unsaturated soil is usually assumed to be a function of soil suction. The concept of yield stress in classical elastoplasticity theory refers to the stress level that causes plastic deformation. Under isotropic stress states, the yield stress is also called the preconsolidation stress or preconsolidation pressure. For unsaturated soils, this yield net mean stress, denoted here by $\bar{p}_{\mathrm{c}}$, is usually determined from compression curves obtained under constant suctions. These compression curves are usually plotted in the space of void ratio versus logarithmic mean stress. The initial portion of the curve is typically flatter than the ending portion of the curve, if the suction is larger than zero, both for slurry soils and for compacted soils. Such a curve is then approximated by two straight lines: one representing the elastic unloading-reloading line and the other the elastoplastic-normal compression line. The meeting point of the two lines gives the preconsolidation 
Fig. 1. Isotropic compression curves under constant suction $(s)$ and derived yield stresses. (a) Isotropic compression curves; $(b)$ variation of preconsolidation stress versus suction. $e$, void ratio; $s$ soil suction; subscripts 1,2 , and 3 represent three different suction values.

(a)

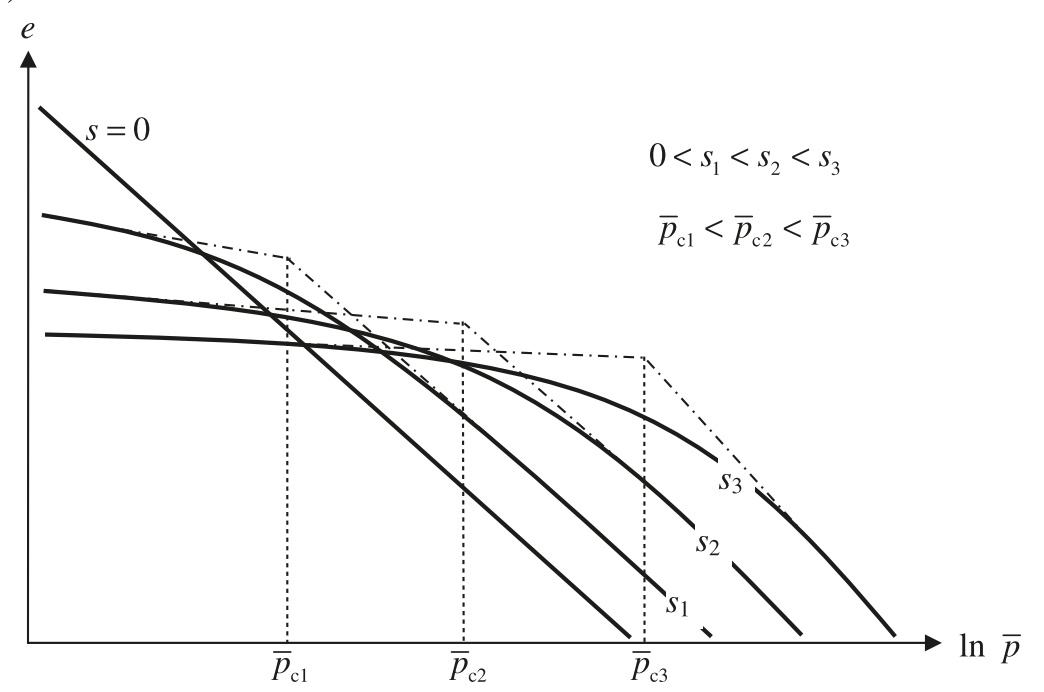

(b)

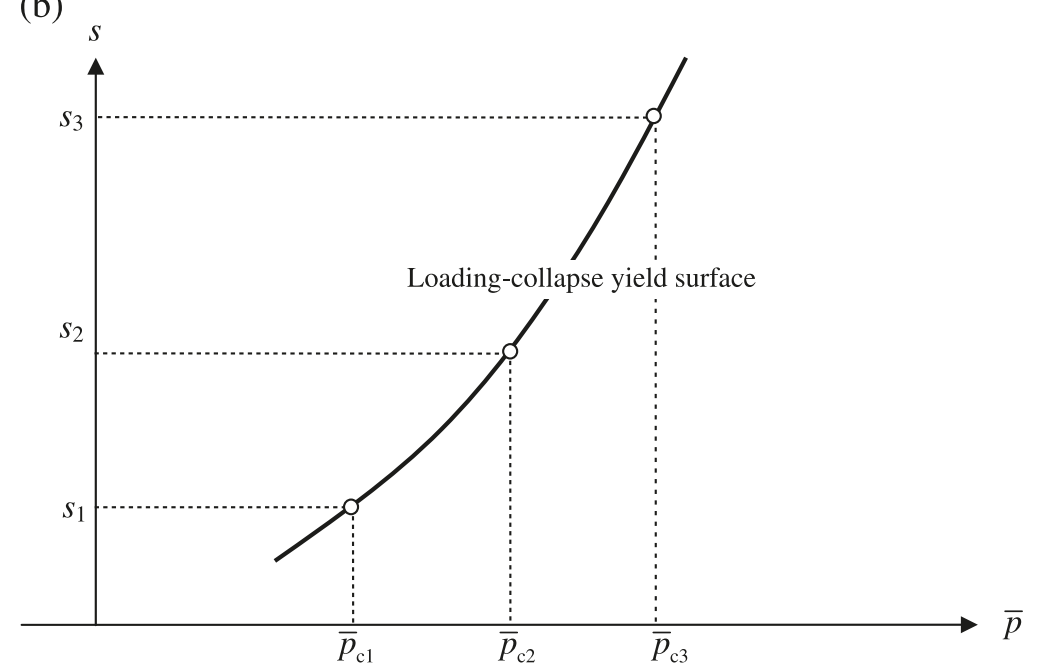

stress or yield stress (Fig. $1 a$, where $\bar{p}$ denotes the mean net stress). The yield stress so determined is generally found to increase with increasing suction, irrespective of whether the samples are prepared from slurry or from compacted soils, leading to the so-called apparent consolidation concept and the loading-collapse yield surface that is widely used in constitutive models for unsaturated soils (Fig. 1b).

The procedure outlined above for determining the yield stress for unsaturated soils has a significant shortcoming. To demonstrate this shortcoming, we should first realize that the isotropic compression curves shown in Fig. $1 b$ are typital for unsaturated soils prepared from slurry (e.g., Jennings and Burland 1962) as well as for compacted soils (e.g., Wheeler and Sivakumar 2000). Because it is easier to understand the preconsolidation stress for a slurry soil than for a compacted soil, we use a slurry soil as an example here. Let us assume that the slurry soil was isotropically consolidated to point $\mathrm{F}$ in Fig. 2 and it has an air entry indicated by the suction at point C. Because of the effective stress principle for saturated soils, the initial elastic zone is bounded by the two thick lines that go through points $\mathrm{A}$ and $\mathrm{F}$ and are in- clined to the horizontal by $135^{\circ}$. The yield stress at suction of point B is then zero. Drying this slurry soil under zero mean stress to a suction at point $\mathrm{C}$ will cause plastic yielding. The yield stress at zero suction will increase to the mean stress at point $\mathrm{G}$, but the yield stress at the current suction remains zero (point C). Further drying will cause desaturation of the soil, but the yield stress at zero suction will generally not increase at the same rate as the suction. If the soil is dried under zero stress to the suction at point $\mathrm{D}$, the yield stress at zero suction will then be somewhere between point $\mathrm{G}$ and point I (point $\mathrm{H}$ in Fig. 2). Next, the soil is isotropically compressed under constant suction at point $\mathrm{D}$ (i.e., stress path DE in Fig. 2). According to the data by Jennings and Burland (1962) and more recently by Cunningham et al. (2003), the isotropic compression line in the space of void ratio against logarithmic mean stress will be curved, in a pattern as the curves shown in Fig. $1 a$ for $s>0$. However, the isotropic compression path (DE) is clearly outside the current elastic zone and the yield (preconsolidation) stress increases from zero to the current stress level. Therefore, the isotropic compression path (as well as the drying path 
Fig. 2. (a) Expansion of the elastic zone during drying and compression of a slurry soil; $(b)$ corresponding volume change. NCL, normal compression line.

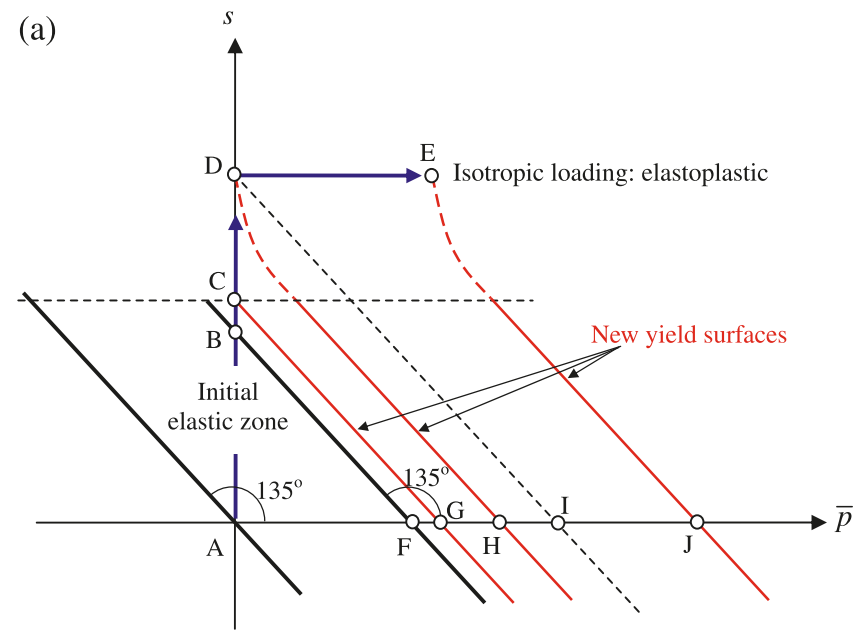

(b)

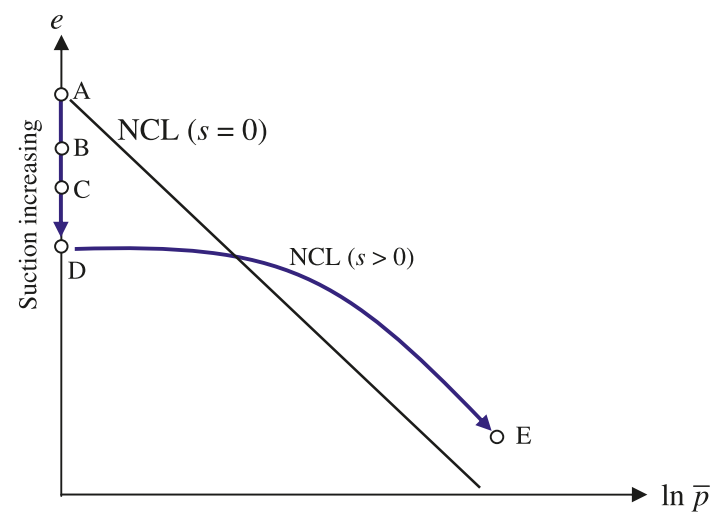

from $\mathrm{C}$ to $\mathrm{D})$ is elastoplastic and does not involve a purely elastic portion as Fig. 1 indicates, suggesting that the method for determining the yield stress in Fig. $1 b$ is incorrect. Indeed, the effect of suction on the preconsolidation stress should refer to the increase of the preconsolidation stress at zero suction $\left(\bar{p}_{\mathrm{c}}(0)\right.$ moves from $\mathrm{F}$ to $\mathrm{H}$ as suction increases from $\mathrm{B}$ to $\mathrm{D}$ in Fig. 2), not the preconsolidation stress at current suction $\left(\bar{p}_{\mathrm{c}}(s)=0\right.$ for points $\mathrm{B}, \mathrm{C}$, and D).

Very recently, Sheng et al. (2008a) proposed a new modelling approach for unsaturated soils. In this approach, yield stress and shear strength of unsaturated soils were derived from the volumetric model that defines the volume change caused by suction and mean stress changes. A specific model was proposed and it was called the SFG model, after the three authors' surnames, i.e., Sheng, Fredlund, and Gens. An essential difference between the SFG model and the other elastoplastic models in the literature is that the former provides a consistent explanation of yield stress, shear strength, and volume change behaviour of unsaturated soils as functions of suction, both for soils prepared from slurry and from compacted specimens. It was shown that all these functions are actually based on one simple equation that defines the volume change caused by suction and stress changes. This equation is written in an incremental form and provides a continuous and smooth treatment of suction or pore-water pressure for both saturated and unsaturated states. This paper provides a systematic validation of the SFG model against experimental data, in terms of volume change and shear strength behaviour. The experimental data used here include those for samples prepared from slurry and from compacted soils.

\section{Volume change behaviour}

In the SFG model by Sheng et al. (2008a), the change of the soil volume can be caused by a change in mean stress or a change in soil suction. For normally consolidated soils under isotropic stress states, we have

$$
\text { [1] } \mathrm{d} v=-\lambda_{\mathrm{vp}} \frac{\mathrm{d} \bar{p}}{\bar{p}+s}-\lambda_{\mathrm{vs}}(s) \frac{\mathrm{d} s}{\bar{p}+s}
$$

where $v$ is the specific volume and $v=1+e, e$ is the void ratio, $\lambda_{\mathrm{vp}}$ is a parameter related to the soil compressibility in terms of stress changes, and $\lambda_{\mathrm{vs}}$ is a parameter related to the soil compressibility in terms of suction changes, $\bar{p}=p-u_{\mathrm{a}}$, $p$ is the mean stress and $p=\left(\sigma_{1}+\sigma_{2}+\sigma_{3}\right) / 3$ (where $\sigma_{1}, \sigma_{2}$, and $\sigma_{3}$ are the first, second, and third principle stresses, respectively), $u_{\mathrm{a}}$ is the pore-air pressure, $s$ is the soil suction and $s=u_{\mathrm{a}}-u_{\mathrm{w}}$, and $u_{\mathrm{w}}$ is the pore-water pressure. The soil suction used in this paper refers to the matric suction, which consists of a capillary and an adsorptive component. When the pore water exists as capillary water at relatively high degrees of saturation, the capillary potential $\left(\psi_{\mathrm{c}}\right)$ is dominant in the matric suction $s=\psi_{\mathrm{c}}=u_{\mathrm{a}}-u_{\mathrm{w}}$. When the pore water exists as adsorbed water films in the soil, the adsorptive potential $\left(\psi_{\mathrm{a}}\right)$ becomes dominant in the matric suction. In this case, the true water pressure is not well defined as it is not unique at one material point and is dependent on the proximity to the particle surface. An apparent water pressure can be introduced to quantify the adsorptive potential: $u_{\mathrm{W}}=u_{\mathrm{a}}$ $\psi_{\text {a }}$, i.e., the apparent water pressure represents the negative adsorptive potential measured in excess of air pressure. When the air pressure is atmospheric (0), the apparent water pressure is then the negative adsorptive potential and the net mean stress becomes the total mean stress. Such an apparent water pressure is then unique at one material point. With this definition of $u_{\mathrm{W}}$, the matric suction can be expressed as $s=$ $u_{\mathrm{a}}-u_{\mathrm{W}}$ and can be used continuously for a relatively large range of saturation - from fully saturated to very dry states.

The parameter $\lambda_{\mathrm{vp}}$ can be determined from normal compression lines (NCL) for $s=0$. It is the same as the slope $(\lambda)$ of NCL in $e-\ln p$ plots that are commonly used for saturated soils. In its simplest form, this parameter can be treated as a constant for one soil, but more realistically it should be a function of suction. The parameter $\lambda_{\mathrm{vs}}$ is a function of suction. Its initial value is the same as $\lambda_{v p}$ for suctions below the saturation suction, but it approaches zero as suction increases to infinity. The following simple equation was used in Sheng et al. (2008a):

[2] $\quad \lambda_{\mathrm{vs}}= \begin{cases}\lambda_{\mathrm{vp}} & s<s_{\mathrm{sa}} \\ \lambda_{\mathrm{vp}} \frac{s_{\mathrm{sa}}+1}{s+1} & s \geq s_{\mathrm{sa}}\end{cases}$

where $s_{\mathrm{sa}}$ is the saturation suction and its definition is slightly different from the air-entry value (see Sheng et al. 2008a). 
The volumetric model defined by eqs. [1] and [2] is the foundation of the SFG model. The yield stress and shear strength criteria in the SFG model are all based on this volumetric model. It is very simple and the only additional parameter needed for unsaturated states is the saturation suction. Its validity will be tested against experimental data for different types of unsaturated soils in this paper. In the original model by Sheng et al. (2008a), the plastic volumetric strain rate $\left(\mathrm{d} \varepsilon_{\mathrm{v}}^{\mathrm{p}}\right)$ was used in place of the negative volume rate $(-\mathrm{d} v)$ in eq. [1], which leads to a linear relationship in the double logarithmic space of $\ln v-\ln p$. However, experimental data and associated parameters (such as $\lambda$ ) in the literature are usually presented in the semi-logarithmic space of $v-\ln p$. Therefore, the semi-logarithmic relation is used in this paper to simplify the comparison. The two alternatives have no essential difference because the variation of the specific volume is usually less than one order of magnitude.

One obvious shortcoming of eq. [1] is that it predicts an incompressible soil when the suction becomes very large, due to the term $\bar{p}+s$. This is of course not true in real soil behaviour, as a dry sand is still compressible at high stresses. According to Sheng et al. (2008a), a possible modification to eq. [1] is to introduce the residual suction into the equation and to use it as a threshold to suctions applied in the equation. Such a modification is expected to improve its prediction for sandy soils where the residual suction is typically in the range of $10-1000 \mathrm{kPa}$. However, the simpler form is used for all predictions presented in this paper.

\section{Volume changes for soils prepared from slurry}

Data on unsaturated soils air-dried from slurry are not common in the literature. They often represent the missing piece in the puzzle of unsaturated soil behaviour. Two such sets of data are provided by Jennings and Burland (1962) and by Cunningham et al. (2003).

Jennings and Burland (1962) conducted a series of oedometer and isotropic compression tests on a range of unsaturated silty soils that were air-dried or soaked from consolidated slurry samples. Suction was not controlled or measured during oedometer or isotropic compression tests, which makes it difficult to compare the data with the SFG model. Only the volume versus suction curve under constant (0) stress can be used to validate eqs. [1] and [2]. In Fig. 3, the predicted void ratio versus suction curve is compared with data by Jennings and Burland (1962). In this figure, the parameters $\lambda_{\mathrm{vp}}$ and $s_{\mathrm{sa}}$ are estimated for the silty soil tested. The soil was assumed to be normally consolidated. It is shown that the prediction compares quite well with the data.

Jennings and Burland (1962) also provided various oedometer compression curves. Unfortunately, the suction was not controlled or measured in their tests, which makes it difficult to compare the data with the model prediction. However, the compression curves obtained from their tests show a very similar pattern to the prediction of eq. [1]. In particular, Figs. 2, 3, 6, 9, and 10 in Jennings and Burland (1962) are all comparable to Fig. 4 in Sheng et al. (2008a).

More recently, Cunningham et al. (2003) presented the results of a series of isotropic compression tests on the reconstituted silty clay that comprised a mix of $20 \%$ pure Speswhite kaolin, 10\% London clay, and 70\% silica silt.
The soil-water characteristic curve is plotted in Fig. 4, where the approximation according to the SFG model by Sheng et al. (2008a) is also shown. The slurry soil was isotropically preconsolidated to $130 \mathrm{kPa}$. Other parameters needed for predictions are given in Cunningham et al. (2003): $\lambda_{\mathrm{vp}}=0.043, \kappa_{\mathrm{vp}}=0.007$, and $s_{\mathrm{sa}}=250 \mathrm{kPa}$. The parameter $\kappa_{\mathrm{vp}}$ is the slope of the unloading-reloading line in $e-$ $\ln p$ plots. In Fig. 5, the predicted void ratio versus suction curve under constant stress is compared with the data by Cunningham et al. (2003). Again, we see that the prediction according to eqs. [1] and [2] matches well the experimental data.

The predicted isotropic compression curves are compared with the experimental data of Cunningham et al. (2003) in Fig. 6. It is observed that the experimental isotropic compression curves for suctions larger than zero don't have a clear point of slope changes (unlike the curve for zero suction). Because the suctions $(400,650$, and $1000 \mathrm{kPa})$ are larger than the air-entry value of the soil, the corresponding isotropic compression curves are actually all normal compression lines. They are curved in the $e-\ln p$ space because of the combined effects of suction and mean stress. Using the method outlined in Fig. 1 to determine the yield stress would clearly lead to a wrong conclusion. The predicted curves agree very well with the experimental data.

\section{Volume changes for compacted soils}

As shown by Sheng et al. (2008a), the shape of the yield stress loci in the $s-p$ space for a slurry soil is indeed similar to those shown in Fig. 2. However, compaction or isotropic compression at suctions higher than the air-entry value can change the shape of the yield stress loci, e.g., from $\bar{p}_{\mathrm{c}}$ to $\bar{p}_{\text {cn }}$ as demonstrated in Fig. 7 ( $\bar{p}_{0}$ in this figure represents the apparent tensile strength). The reason for this change is that the stress increments required to generate the same amount of plastic volumetric strain will depend on the suction level. Starting from the current yield loci defined by $\bar{p}_{\mathrm{c}}$ in Fig. 7, a new yield surface $\bar{p}_{\mathrm{cn}}$ represents a contour of plastic volumetric strain for an isotropically hardening material where the plastic volumetric strain is the hardening parameter. The stress increments required to generate the same amount of plastic volumetric strain at the three suction levels $\left(s_{1}, s_{2}\right.$, and $\left.s_{3}\right)$ are different, leading to a new yield surface of the shape shown by $\bar{p}_{\mathrm{cn}}$ in Fig. 7 .

Therefore, the yield (preconsolidation) stress for compacted soils cannot be determined as easily as that for a slurry soil. A typical isotropic compression curve for a compacted soil is shown in Fig. 8, with data by Sivakumar and Wheeler (2000). The isotropic compression curve for $s=0$ is also plotted in the figure for reference. For the saturated soil $(s=0)$, the preconsolidation stress can be determined straightforwardly (point A). For the unsaturated soil $(s=$ $300 \mathrm{kPa}$ ), we would get the stress at point B as the preconsolidation stress if we use the method outlined in Fig. 1. However, as discussed before, this yield stress is likely to be wrong. If we use eq. [1] to approximate the experimental data, we would get the stress at point $\mathrm{C}$ as the preconsolidation stress, which is smaller than the stress at point $\mathrm{B}$. The predicted normal compression line according to eq. [1] is curved and fits the experimental data quite well. Due to the compaction process, the initial portion of the 
Fig. 3. Comparison of eq. [2] with data by Jennings and Burland (1962).

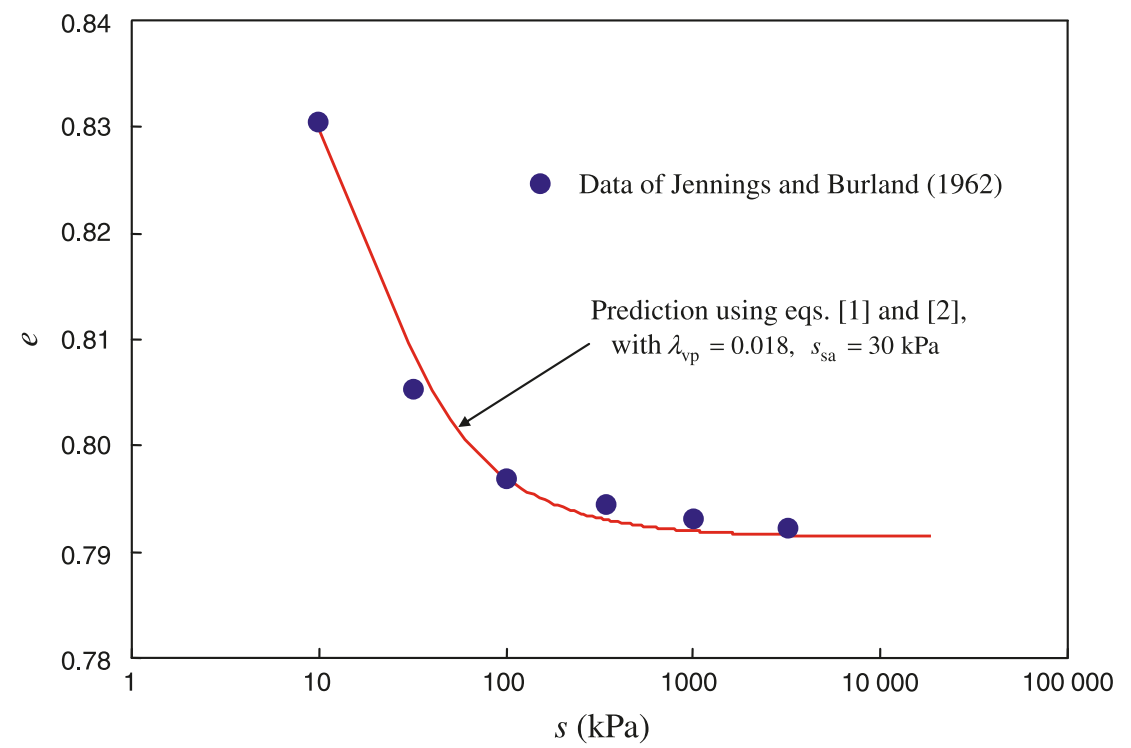

Fig. 4. Soil-water characteristic curve for the soil tested by Cunningham et al. (2003). $s_{\text {ae, }}$ air-entry value; $s_{\text {re, }}$, residual suction.

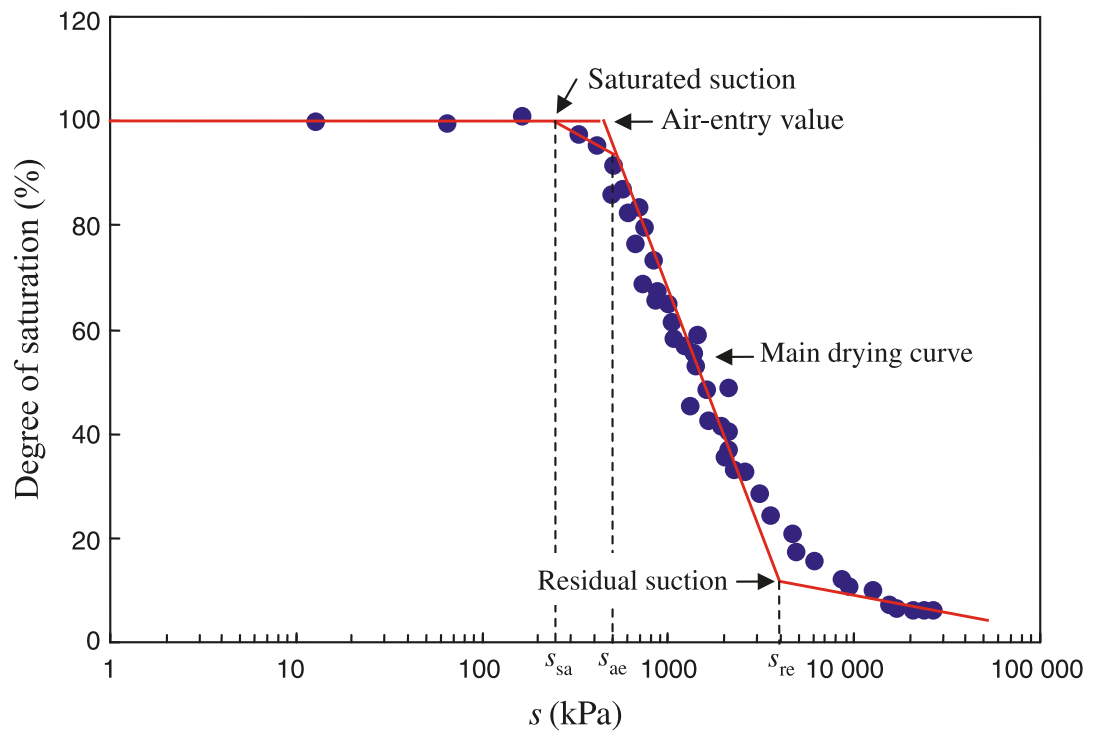

isotropic compression curve is likely to follow the elastic unloading-reloading curve.

Thu et al. (2007) also presented a series of isotropic compression test results on compacted kaolin specimens (made of $15 \%$ clay and $85 \%$ silt). The test results and the predictions are compared in Figs. $9 a-9 e$. The material parameters used in the prediction are also given Fig. 9. It is shown that the isotropic compression curves are very well predicted by the SFG model.

Marinho et al. (1995) presented the results of a series of drying tests carried out on compacted specimens of highplasticity clay (the brown London clay). The measured void ratios are plotted against suction in Fig. 10, where the predictions by eqs. [1] and [2] are also shown for comparison. The parameters used for the predictions are listed in Fig. 10. The parameter $\lambda_{\mathrm{vp}}$ for different series is not a constant, even though its variation is not large. It is generally true that $\lambda_{\mathrm{vp}}$ will vary between samples for compacted soils, even though the compaction process is identical. The saturation suction was estimated according to the soil-water characteristic curve in Marinho et al. (1995). Again, Fig. 10 shows that eqs. [1] and [2] can predict the volume change caused by suction change quite well.

\section{Shear strength behaviour}

The shear strength of an unsaturated soil is usually considered to be a function of suction (Fredlund et al. 1978; Escario and Saez 1986; Vanapalli et al. 1996; Toll and Ong 2003). Sheng et al. (2008a) showed that the shear strength criterion can be derived from the yield stress function, which in turn is derived from the volumetric model. For the SFG model, the yield stress function for a slurry soil is defined by 
Fig. 5. Comparison of eq. [2] with data by Cunningham et al. (2003).

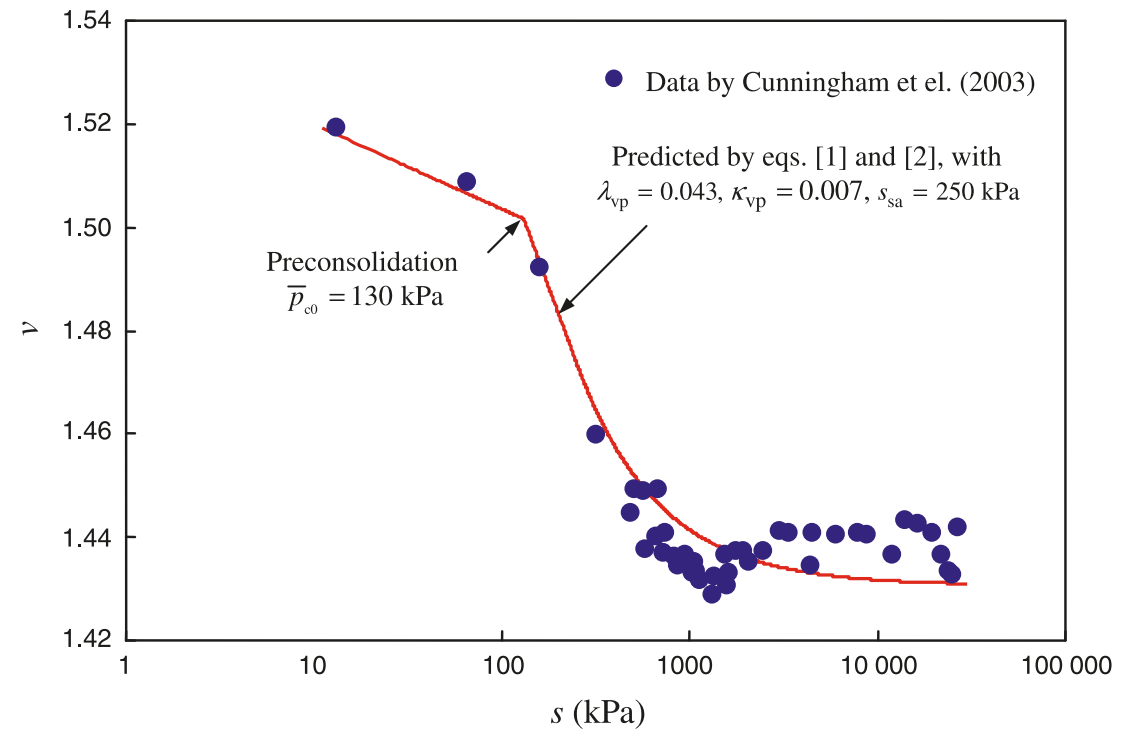

Fig. 6. Predicted isotropic compression curves versus data by Cunningham et al. (2003).

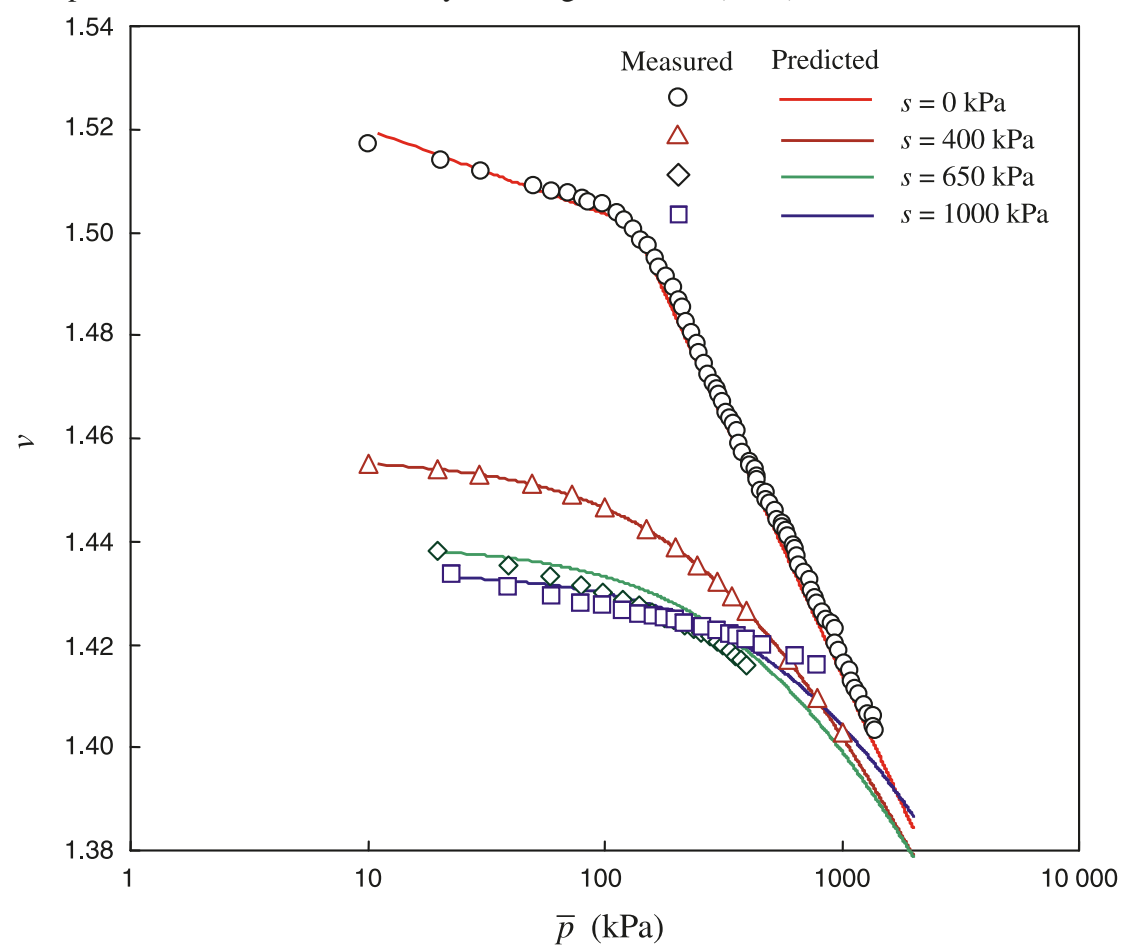

[3] $\quad \bar{p}_{0}= \begin{cases}-s & s<s_{\mathrm{sa}} \\ -s_{\mathrm{sa}}-\left(s_{\mathrm{sa}}+1\right) \ln \frac{s+1}{s_{\mathrm{sa}}+1} & s \geq s_{\mathrm{sa}}\end{cases}$

A slurry soil has no shear strength if the mean stress and suction vary according to eq. [3]. Equation [3] also indicates that the slurry soil is still at a slurry state if one of the following three conditions exists:

(1) The mean stress and suction are both kept zero (i.e., the point at origin in Fig. 7).

(2) Both the pore-water pressure and the mean stress increases at the same rate when $s<s_{\text {a }}$ (i.e., the part of $\bar{p}_{0}$ curve that follows the $135^{\circ}$ line in Fig. 7).
(3) The mean stress decreases according to $-s_{\mathrm{sa}}-\left(s_{\mathrm{sa}}+\right.$ $1) \ln \left[(s+1) /\left(s_{\mathrm{sa}}+1\right)\right]$ as suction increases when $s \geq s_{\mathrm{sa}}$ (i.e., the part of $\bar{p}_{0}$ curve beyond saturated suction in Fig. 7).

The yield stress defined by $\bar{p}_{0}$ is a fundamental property of the soil and it is often missing in other constitutive models for unsaturated soils. The shape of $\bar{p}_{0}$ is shown in Fig. 7. Drying a slurry under constant stresses does not change the shape of this yield stress loci, but only pushes it upwards by expanding the elastic zone (see Fig. 2).

Equation [3] can be used to define the apparent tensile strength of the soil as a function of suction. The apparent cohesion due to suction is then 
Fig. 7. Yield surface change due to compaction or isotropic compression $\left(s_{\mathrm{sa}}=100 \mathrm{kPa}\right)$.

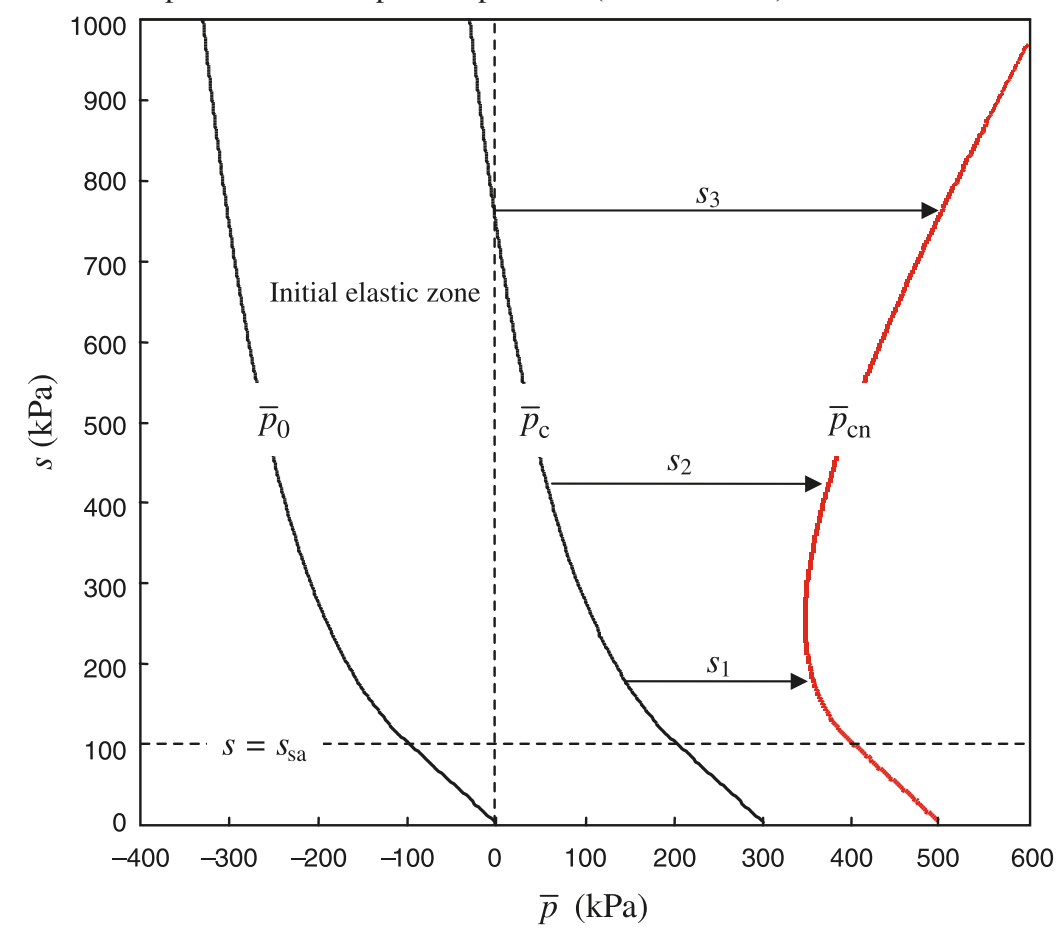

Fig. 8. Isotropic compression curves (data from Sivakumar and Wheeler 2000).

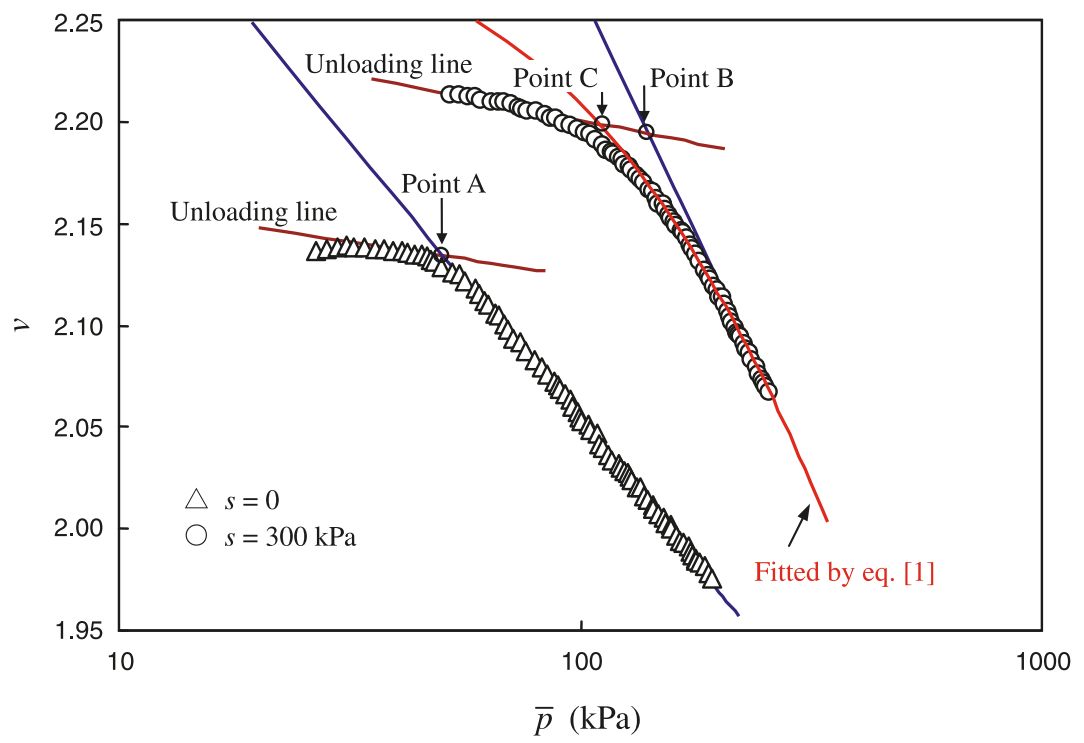

[4] $\quad \bar{c}=-\bar{p}_{0} \tan \phi^{\prime}+c^{\prime}$

$$
= \begin{cases}c^{\prime}+s \tan \phi^{\prime} & s<s_{\mathrm{sa}} \\ c^{\prime}+\tan \phi^{\prime}\left[s_{\mathrm{sa}}+\left(s_{\mathrm{sa}}+1\right) \ln \frac{s+1}{s_{\mathrm{sa}}+1}\right] & s \geq s_{\mathrm{sa}}\end{cases}
$$

where $\phi^{\prime}$ is the effective friction angle of the soil and $c^{\prime}$ is the effective-stress cohesion for saturated soils and is usually zero unless the soil is cemented. Fredlund et al. (1978) proposed the following shear strength criterion:

$$
\text { [5] } \begin{aligned}
\tau & =\left[c^{\prime}+\left(\sigma_{\mathrm{n}}-u_{\mathrm{a}}\right) \tan \phi^{\prime}\right]+\left[\left(u_{\mathrm{a}}-u_{\mathrm{w}}\right) \tan \phi^{\mathrm{b}}\right] \\
& =\bar{c}+\left(\sigma_{\mathrm{n}}-u_{\mathrm{a}}\right) \tan \phi^{\prime}
\end{aligned}
$$

where $\tau$ is the shear strength, $\sigma_{\mathrm{n}}$ is the normal stress on the failure plane, and $\phi^{\mathrm{b}}$ is the frictional angle due to suction.
Obviously, if $\phi^{\mathrm{b}}$ is set to $\phi^{\prime}$ in eq. [5], the effective stress principle for saturated soils is recovered. Combining eqs. [4] and [5] leads to

[6] $\tan \phi^{\mathrm{b}}= \begin{cases}\tan \phi^{\prime} & s<s_{\mathrm{sa}} \\ \tan \phi^{\prime}\left[\frac{s_{\mathrm{sa}}}{s}+\left(\frac{s_{\mathrm{sa}}+1}{s}\right) \ln \frac{s+1}{s_{\mathrm{sa}}+1}\right] & s \geq s_{\mathrm{sa}}\end{cases}$

In this case, the friction angle $\phi^{\mathrm{b}}$ is a function of suction as well as saturation suction. Equation [6] can be used to predict the change of the shear strength against suction.

Cunningham et al. (2003) presented a set of triaxial compression tests with various confining pressures on the reconstituted silty clay mentioned above. The test results are 
Fig. 9. Predictions of isotropic compression curves for compacted kaolin specimen (data from Thu et al. 2007).

Material parameters used in the prediction
\begin{tabular}{|c|c|c|c|c|c|l|}
\hline & $s(\mathrm{kPa})$ & $\lambda_{\mathrm{vp}}$ & $\kappa_{\mathrm{vp}}$ & $\bar{p}_{\mathrm{c}}$ & Data & Predictions \\
\hline (a) & 0 & 0.058 & 0.018 & $25 \mathrm{kPa}$ & $\bullet$ & \\
\hline (b) & 50 & 0.058 & 0.018 & $35 \mathrm{kPa}$ & $\square$ & \\
\hline (c) & 100 & 0.058 & 0.018 & $25 \mathrm{kPa}$ & $\triangle$ & \\
\hline (d) & 150 & 0.058 & 0.018 & $35 \mathrm{kPa}$ & $\diamond$ & \\
\hline (e) & 200 & 0.058 & 0.018 & $35 \mathrm{kPa}$ & $\bigcirc$ & \\
\hline
\end{tabular}
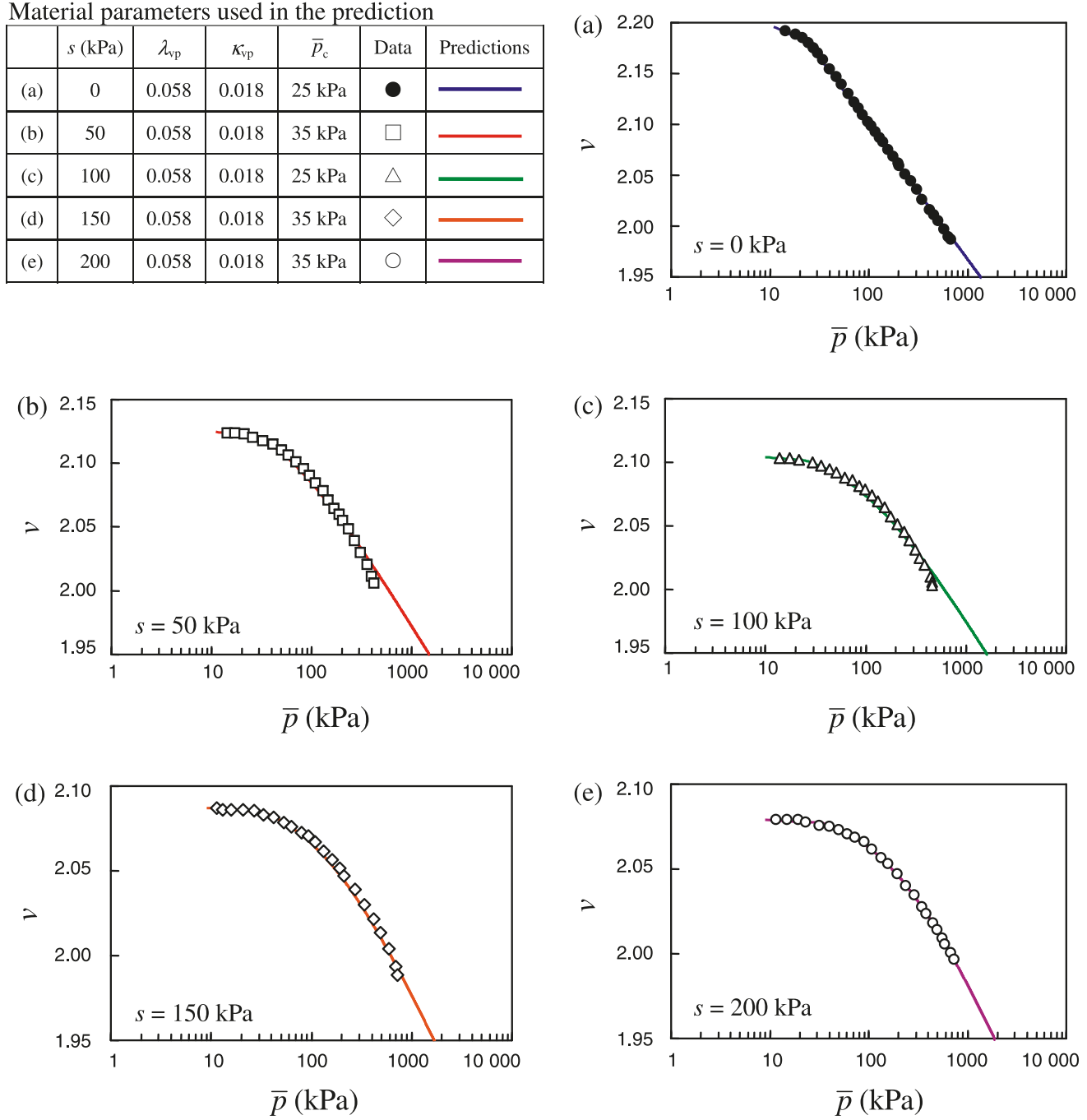

Fig. 10. Volume change during drying for Brown London Clay (data from Marinho et al. 1995).

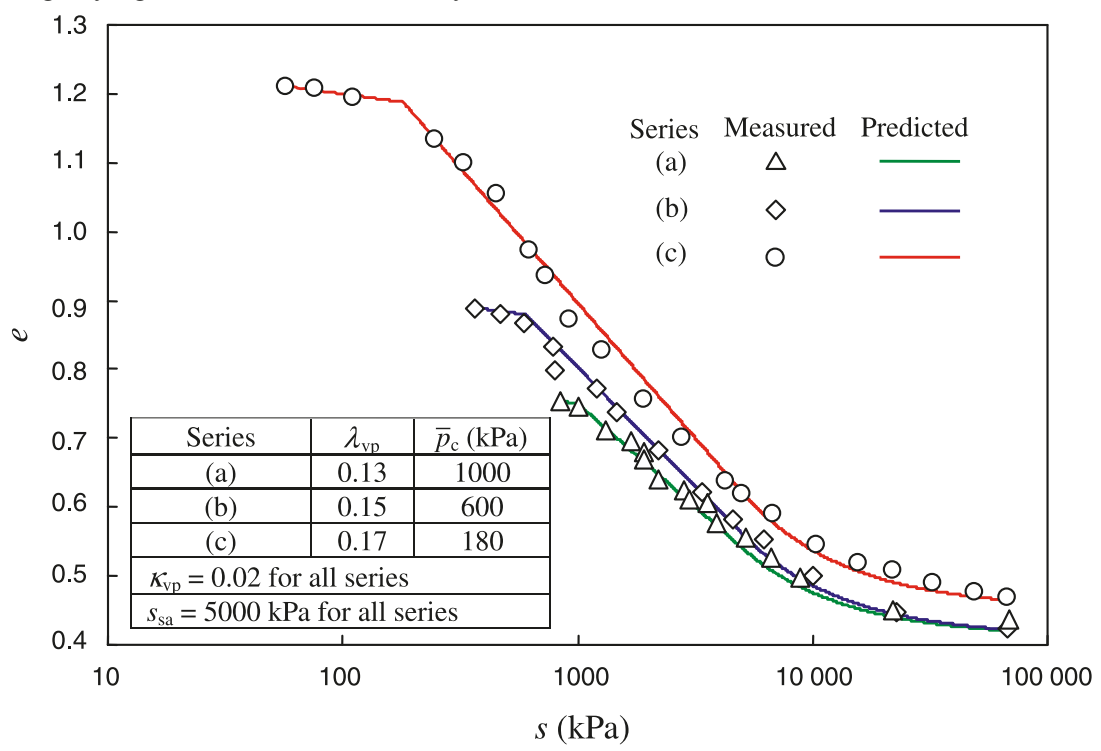


Fig. 11. Shear strength versus suction during triaxial compression tests (data from Cunningham et al. 2003). (a) Unconfined; (b) confining pressure $50 \mathrm{kPa}$; (c) confining pressure $100 \mathrm{kPa}$; (d) confining pressure $200 \mathrm{kPa}$.
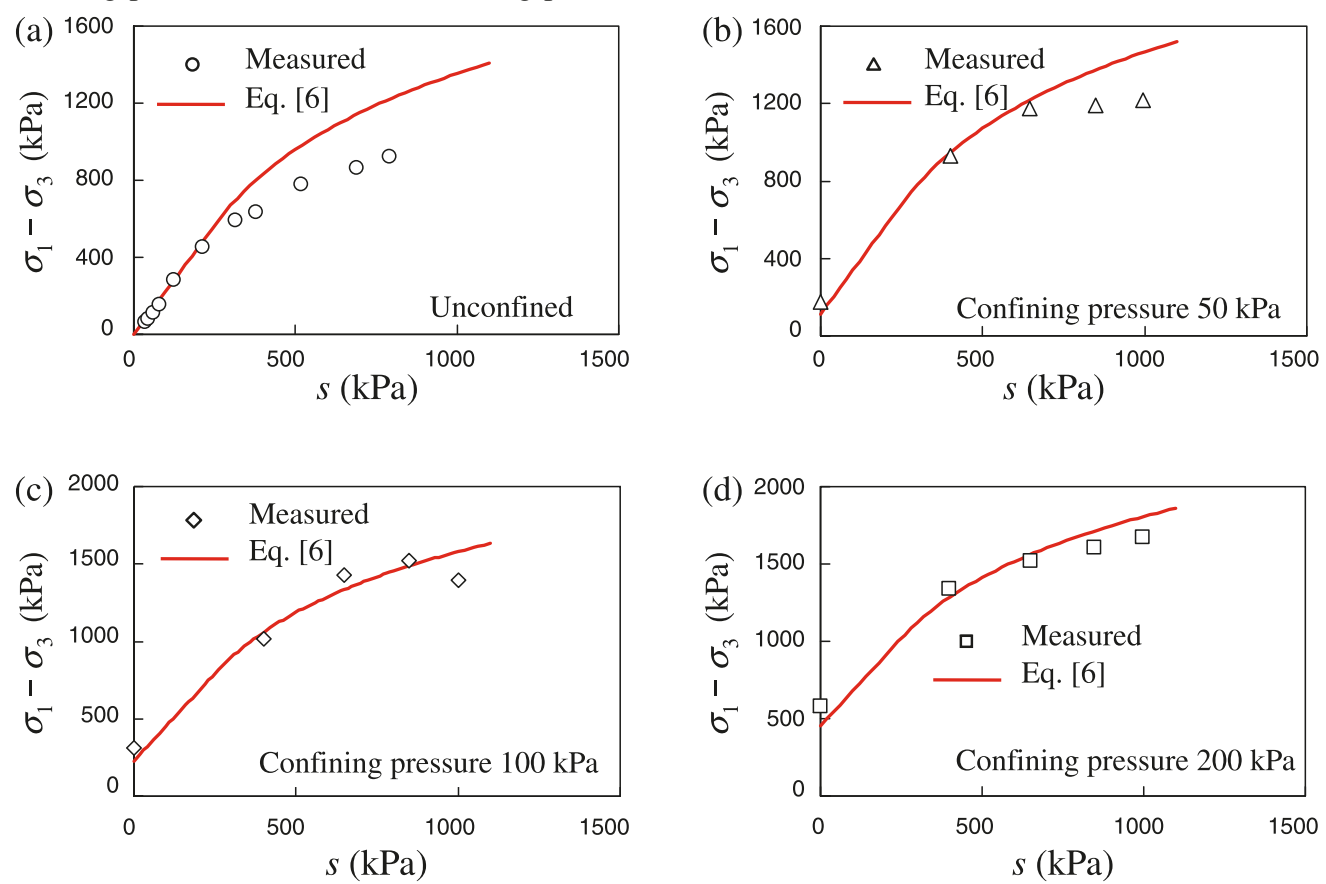

Fig. 12. Shear strength versus suction during triaxial compression tests (data from Röhm and Vilar 1995). (a) Suction $20 \mathrm{kPa}$; (b) suction $50 \mathrm{kPa}$; (c) suction $200 \mathrm{kPa}$; (d) suction $400 \mathrm{kPa}$.
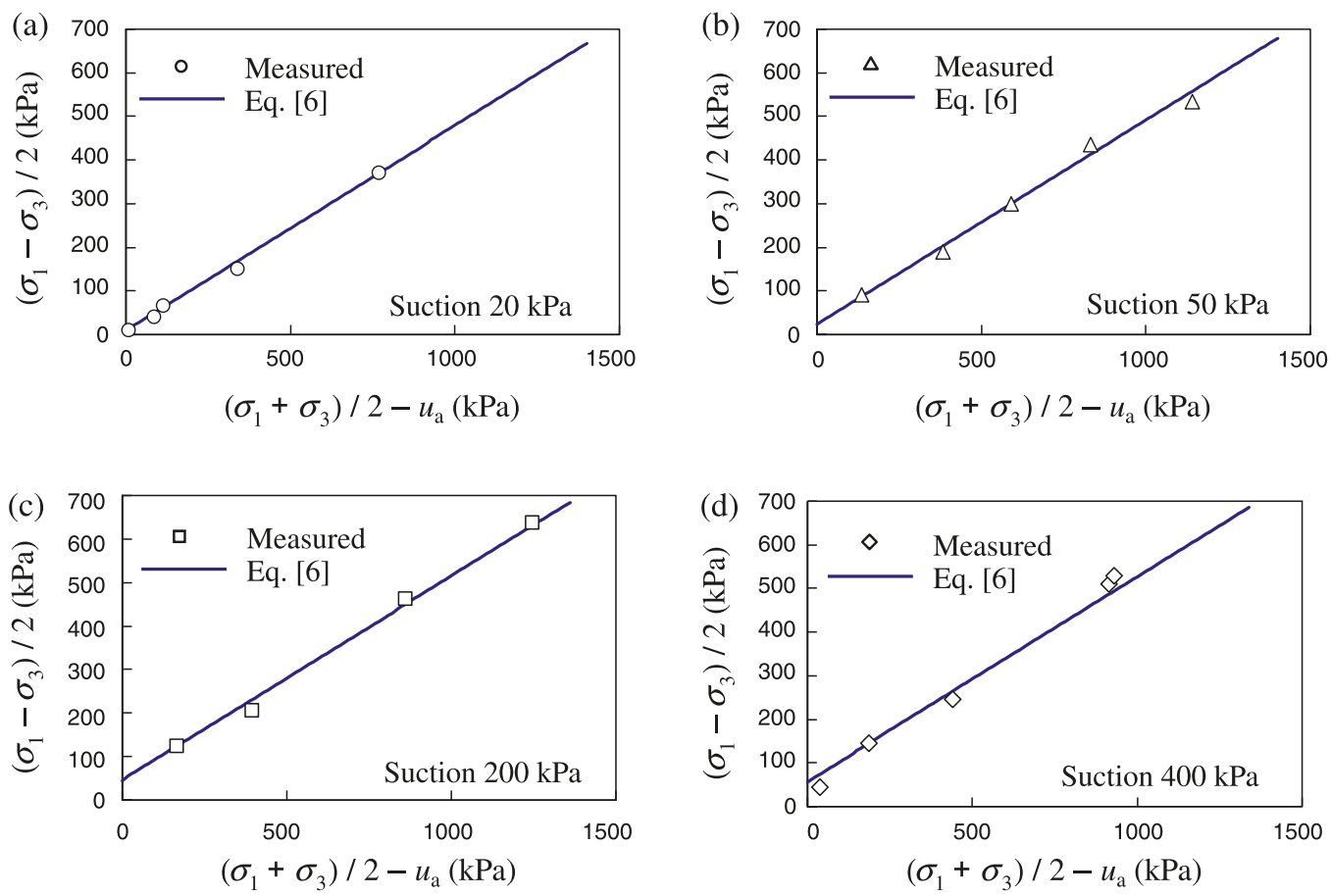

plotted for different confining pressures in Figs. 11a-11c. The parameters used in the predictions were all given in Cunningham et al. (2003) and are as follows: $\phi^{\prime}=32^{\circ}, c^{\prime}=$ $0 \mathrm{kPa}$, and $s_{\mathrm{sa}}=250 \mathrm{kPa}$. Figure 11 shows that the prediction by eq. [6] agrees reasonably well with the experimental data, except that some overestimation of the shear strength is observed for tests with low confining pressures. The test

data also seem to indicate that the shear strength approaches a constant value at smaller suction levels than the predicted response. It should be noted that, in the prediction, the slope of the failure lines in the space of deviator stress versus mean stress is assumed to be constant. Such an assumption is supported by, e.g., Toll (1990), Ng and Chiu (2001), Thu et al. (2006), and Nuth and Laloui (2008). 
Fig. 13. Shear strength versus suction during direct shear tests (data from Vanapalli et al. 1996).

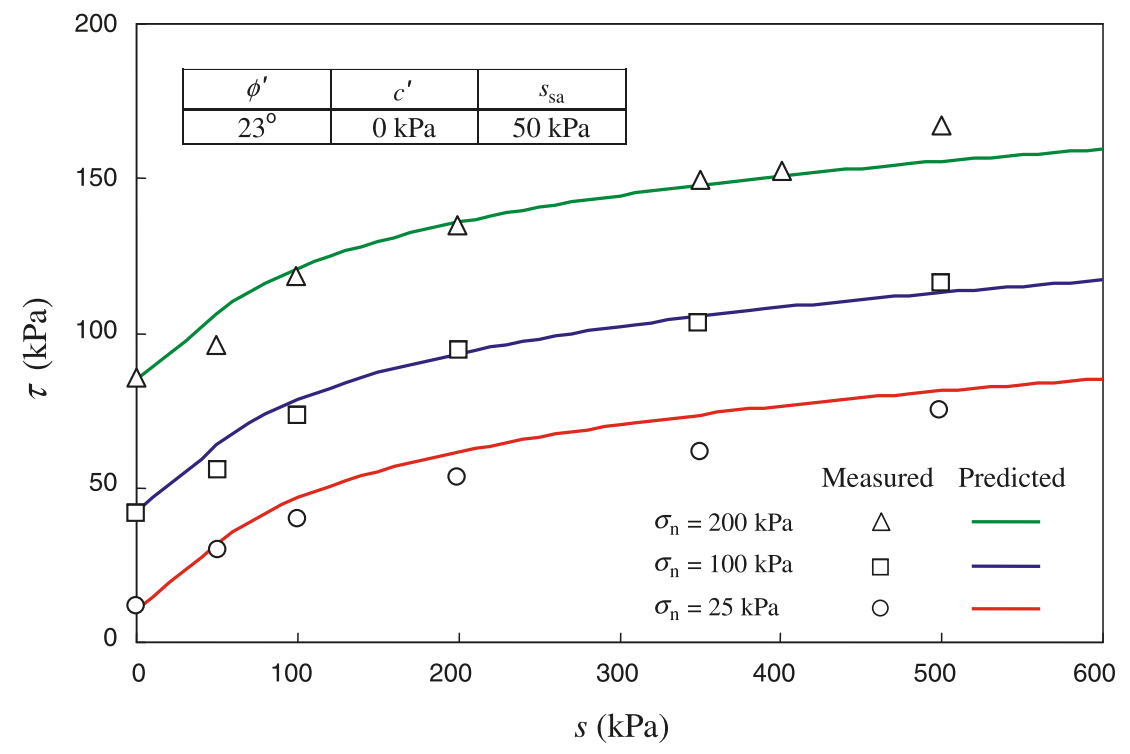

Fig. 14. Shear strength versus suction during triaxial compression tests (data from Wheeler and Sivakumar 2000).

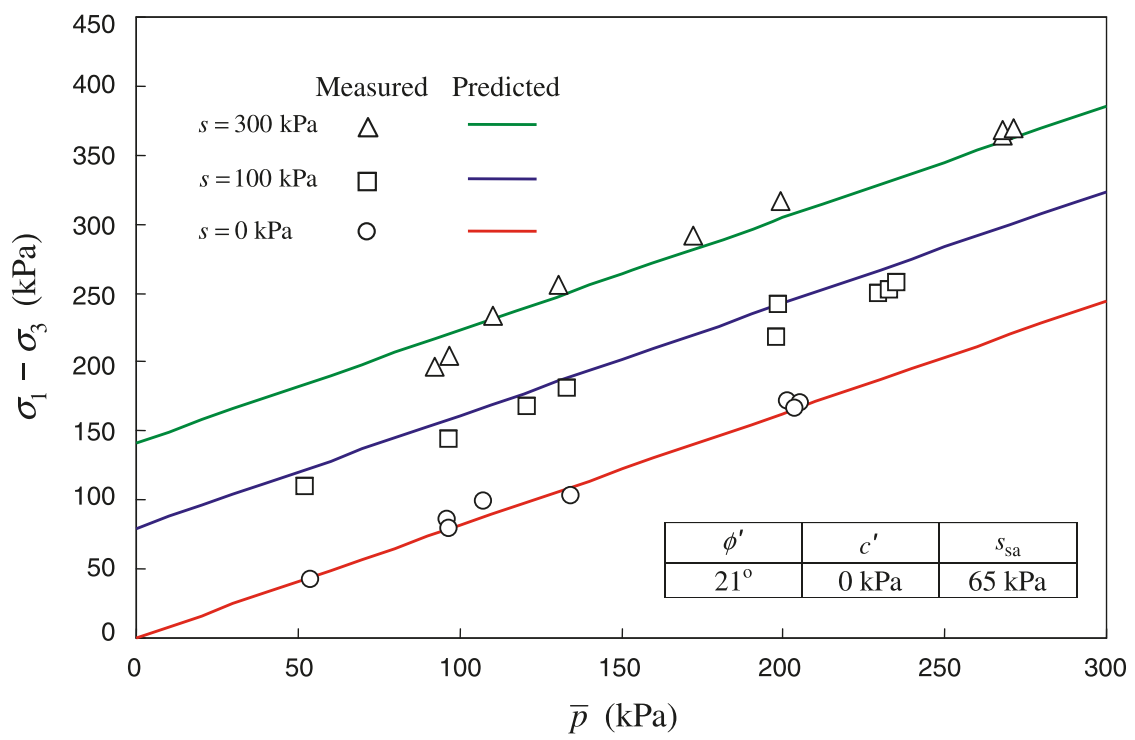

Röhm and Vilar (1995) presented results from a series of triaxial compression tests on a lateritised sandy soil, which is typical in Southeast Brazil. This soil is originated from Bauru and Botucatu sandstones that were eroded, weathered, and deposited as alluvium and colluvium. To set up the desired matric suction, the samples were first allowed to suck water until the matric suction reached approximately zero and then air pressure was raised to obtain the target suctions. Samples were then sheared to failure under triaxial compression. The test results as well as the predictions using eq. [6] are plotted in Fig. 12. The parameters used in the prediction are given as follows: $\phi^{\prime}=28^{\circ}, c^{\prime}=0 \mathrm{kPa}$, and $s_{\mathrm{sa}}=35 \mathrm{kPa}$. Figure 12 shows that the SFG model predicts very well the shear strength behaviour for this soil.

Vanapalli et al. (1996) reported a series of direct shear tests on compacted glacial till obtained from Indian Head, Saskatchewan. Initial water content and dry density of the test sample were $13 \%$ and $1.73 \mathrm{Mg} / \mathrm{m}^{3}$, respectively. The test data and the predictions by eq. [6] are compared in Fig. 13. Once more, the prediction is very good, except that some overestimation is observed for the results with the smallest normal stress.

The triaxial compression test results for compacted kaolin under constant suctions by Wheeler and Sivakumar (2000) are compared with the predictions by the SFG model in Fig. 14. The parameters used in the prediction are given in the figure. The predictions once more match the data very well.

Finally, the direct shear test data by Escario and Saez (1986) are used to further validate the shear strength criterion embodied in the SFG model. The test data included three types of compacted soils; namely, Madrid clay sand, Madrid gray clay, and red silty clay. Figure $15 a$ shows the comparison between the predicted and measured shear 
Fig. 15. Shear strength versus suction during direct shear tests (data from Escario and Saez 1986).
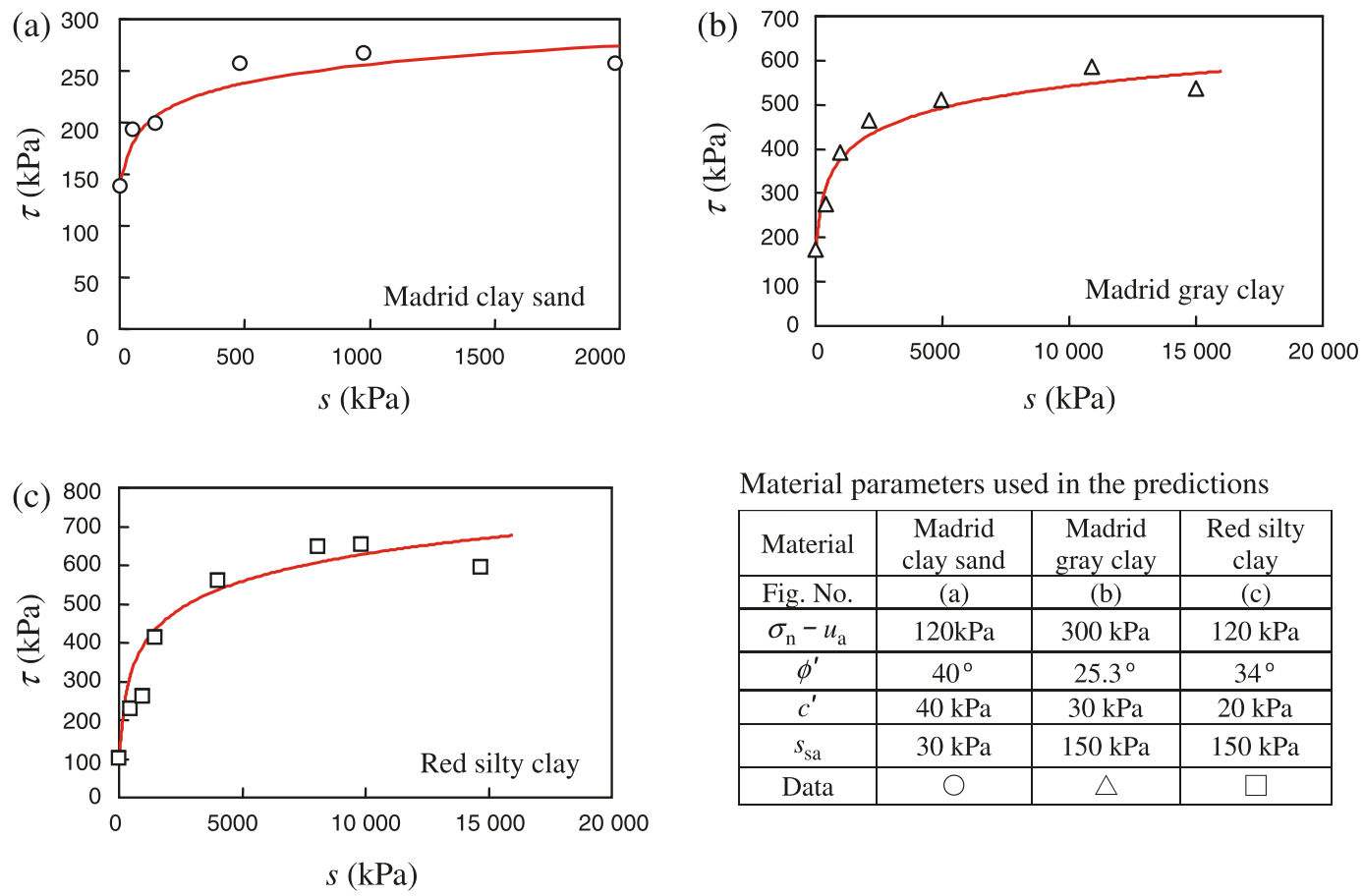

Material parameters used in the predictions

\begin{tabular}{|c|c|c|c|}
\hline Material & $\begin{array}{c}\text { Madrid } \\
\text { clay sand }\end{array}$ & $\begin{array}{c}\text { Madrid } \\
\text { gray clay }\end{array}$ & $\begin{array}{c}\text { Red silty } \\
\text { clay }\end{array}$ \\
\hline Fig. No. & (a) & (b) & (c) \\
\hline$\sigma_{\mathrm{n}}-u_{\mathrm{a}}$ & $120 \mathrm{kPa}$ & $300 \mathrm{kPa}$ & $120 \mathrm{kPa}$ \\
\hline$\phi^{\prime}$ & $40^{\circ}$ & $25.3^{\circ}$ & $34^{\circ}$ \\
\hline$c^{\prime}$ & $40 \mathrm{kPa}$ & $30 \mathrm{kPa}$ & $20 \mathrm{kPa}$ \\
\hline$s_{\mathrm{sa}}$ & $30 \mathrm{kPa}$ & $150 \mathrm{kPa}$ & $150 \mathrm{kPa}$ \\
\hline Data & $\bigcirc$ & $\triangle$ & $\square$ \\
\hline
\end{tabular}

Fig. 16. Effects of saturation suction on the prediction.

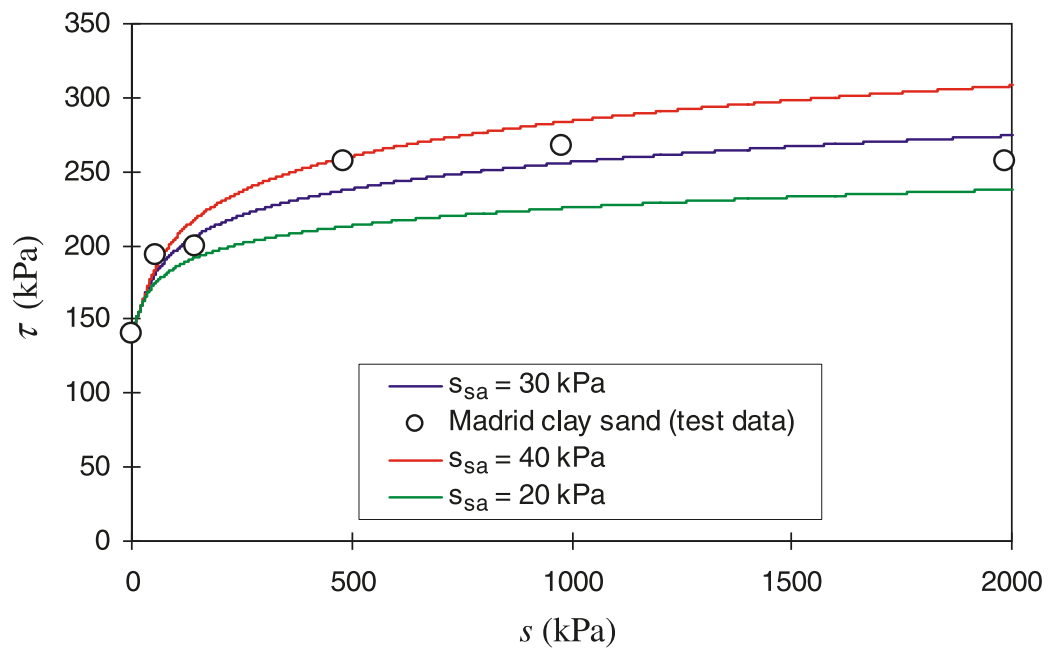

strength values for Madrid clay sand with suction ranging between 0 and $2000 \mathrm{kPa}$. Figure $15 b$ shows the comparisons for Madrid gray clay with suction ranging between 0 and $15000 \mathrm{kPa}$. Figure $15 \mathrm{c}$ shows the comparison for Red silty clay with suction ranging between 0 and $15000 \mathrm{kPa}$. The parameters used in the predictions are given in the figure. Overall, the predictions are reasonable.

In all the calculations above, the parameter $s_{\mathrm{sa}}$ is so chosen to best fit the data. The saturation suction can be determined from the wetting curve (Sheng et al. 2008a). If the wetting curve is not available, the determination of the saturation suction can be subjective. Figure 16 shows the influences of the saturation suction on the predicted shear strength of Madrid clay sand. It is clear that $s_{\text {sa }}$ does affect the prediction. However, the general trend of the curve remains the same.

\section{Concluding remarks}

It should be noted that all soils can be unsaturated with respect to water. In this regard, unsaturated soils are nothing special. The emergence of unsaturated soil mechanics in the last 20 years or so is mainly due to two facts: $(i)$ most soil mechanics principles developed in the first 40 years of soil mechanics history apply to saturated soils only and (ii) the distinct volume, strength, and flow characteristics are observed when certain soils become unsaturated with water. Therefore, the key issue in constitutive modelling of unsaturated soils is how the volume change and shear strength behaviour can be considered in a consistent framework both for saturated and unsaturated states. The modelling approach recently proposed by Sheng et al. (2008a) seems to be able to provide such a consistent framework. 
It was shown that the common procedure to determine the yield stress or preconsolidation stress for unsaturated soils suffers a significant shortcoming and can lead to an incorrect conclusion about the shape of the yield surface. On the other hand, the SFG model recently presented by Sheng et al. (2008a) provides a consistent explanation of yield stress, shear strength, and volume change behaviour of unsaturated soils as functions of suction. All these functions are based on one single equation that defines the volume change with suction and stress changes. Compared with the volumetric model used for saturated clays, this equation has only one additional soil parameter, i.e., the saturation suction (similar to the air-entry value). This paper provides a systematic validation of the equation and the derived shear strength criterion against extensive experimental data in the literature. The experimental data used in the paper include those for samples prepared from slurry soils and compacted soils. The comparison focuses on the volume change caused by suction increases under constant stresses, volume change during isotropic compression tests under constant suctions, and shear strength during direct shear and triaxial compression tests under constant suctions. It was shown that the volume change behaviour and shear strength behaviour of unsaturated soils can very well be predicted by the SFG model.

\section{References}

Cunningham, M.R., Ridley, A.M., Dineen, K., and Burland, J.B. 2003. The mechanical behaviour of a reconstituted unsaturated silty clay. Géotechnique, 53(2): 183-194. doi:10.1680/geot.53.2. 183.37266.

Escario, V., and Saez, J. 1986. The shear strength of partly saturated soils. Géotechnique, 36(3): 453-456.

Fredlund, D.G., Morgenstern, N.R., and Widger, A. 1978. Shear strength of unsaturated soils. Canadian Geotechnical Journal, 15(3): 313-321. doi:10.1139/t78-029.

Jennings, J.E.B., and Burland, J.B. 1962. Limitations to the use of effective stresses in partly saturated soils. Géotechnique, 12(1): 125-144.

Marinho, F.A.M., Chandler, R.J., and Crilly, M.S. 1995. Stiffness measurements on an unsaturated high plasticity clay using bender elements. In Proceedings of the 1st International Conference on Unsaturated Soils, Paris, France, 6-8 September 1995. A.A. Balkema, Rotterdam, the Netherlands. Vol. 2. pp. 535-539.

Ng, C.W.W., and Chiu, A.C.F. 2001. Behaviour of a loosely com- pacted unsaturated volcanic soil. Journal of Geotechnical and Geoenvironmental Engineering, 127(12): 1027-1036. doi:10. 1061/(ASCE)1090-0241(2001)127:12(1027).

Nuth, M., and Laloui, L. 2008. Effective stress concept in unsaturated soils: Clarification and validation of a unified framework. International Journal for Numerical and Analytical Methods in Geomechanics, 32(7): 771-801. doi:10.1002/nag.645.

Röhm, S.A., and Vilar, O.M. 1995. Shear strength of an unsaturated sandy soil. In Proceedings of the 1st International Conference on Unsaturated Soils, Paris, France, 6-8 September 1995. A.A. Balkema, Rotterdam, the Netherlands. Vol. 1, pp. 189-193.

Sheng, D., Fredlund, D.G., and Gens, A. 2008a. A new modelling approach for unsaturated soils using independent stress variables. Canadian Geotechnical Journal, 45(4): 511-534. doi:10. 1139/T07-112.

Sheng, D., Gens, A., Fredlund, D.G., and Sloan, S.W. 2008b. Unsaturated soils: From constitutive modeling to numerical algorithms. Computers and Geotechnics, 35(6): 810-824. doi:10. 1016/j.compgeo.2008.08.011.

Sivakumar, V., and Wheeler, S.J. 2000. Influence of compaction procedure on the mechanical behaviour of an unsaturated compacted clay. Part 1: Wetting and isotropic compression. Géotechnique, 50(4): 359-368.

Thu, T.M., Rahardjo, H., and Leong, E.C. 2006. Shear strength and pore water pressure characteristics during constant water content triaxial tests. Journal of Geotechnical and Geoenvironmental Engineering, 132(3): 411-419. doi:10.1061/(ASCE)1090-0241(2006) 132:3(411).

Thu, T.M., Rahardjo, H., and Leong, E.C. 2007. Soil water characteristic curve and consolidation behaviour of a compacted silt. Canadian Geotechnical Journal, 44(3): 266-275. doi:10.1139/ T06-114.

Toll, D.G. 1990. A framework for unsaturated soil behaviour. Géotechnique, 40(1): 31-44.

Toll, D.G., and Ong, B.H. 2003. Critical state parameters for an unsaturated residual sandy clay. Géotechnique, 53(1): 93-103. doi:10.1680/geot.53.1.93.37255.

Vanapalli, S.K., Fredlund, D.G., Pufahl, D.E., and Clifton, A.W. 1996. Model for the prediction of shear strength with respect to soil suction. Canadian Geotechnical Journal, 33(3): 379-392. doi:10.1139/t96-060.

Wheeler, S.J., and Sivakumar, V. 2000. Influence of compaction procedure on the mechanical behaviour of an unsaturated compacted clay. Part 2: Shearing and constitutive modelling. Géotechnique, 50(4): 369-376. 